\title{
Szkolenie personelu badań nieniszczących w sektorze Utrzymania Ruchu Kolei
}

\author{
Training of Non-Destructive Testing (NDT) personnel \\ in the sector of the Maintenance of Railways
}

\section{Streszczenie}

Bezpieczeństwo zestawów kołowych wymaga przeprowadzania systematycznych badań stanu technicznego zapewniających prawidłową eksploatację transportu szynowego. Badania wizualne w kolejnictwie stanowią podstawowe badania nieniszczące stanowiące podstawę do przeprowadzania innych badań. W sektorze kolejowym przeprowadza się również badania penetracyjne PT i badanie prądami wirowymi ET. Największe zastosowanie znalazły jednak badania magnetyczno-proszkowe MT i ultradźwiękowe UT. Doskonalenie metod badań defektoskopowych prowadzi do konieczności ciągłego szkolenia i kwalifikowania personelu wykonującego badania oraz certyfikacji według określonych w normach zasad w Sektorze Utrzymania Ruchu Kolei.

Słowa kluczowe: Sektor Utrzymania Ruchu Kolei, Badania nieniszczące MT i UT, Badania UT osi kolejowych, Badania MT cewką MINDEN

\section{Abstract}

The security of wheel sets requires carrying out a systematic study of technical condition that will ensure the correct operation of rail transport. Visual testing of the railway is the basic NDT that is then a basis to carry out other tests. There are also Liquid Penetrant Inspection (PT) and Eddy Current Testing (ET) carried out in the rail sector. However, mostly applied are Magnetic Particles Testing (MT) and Ultrasonic Testing (UT). Improving of the methods of defectoscopy (flaw detection tests) leads to the need for continuous training and qualification of the personnel performing the examination, as well as certification according to the rules defined in the standards of the Sector of the Maintenance of Railways.

Keywords: Sector Railway Maintenance, Non-Destructive Testing MT and UT, UT Research rail axes, MT survey coil MINDEN

\section{Wstęp}

Bezpieczeństwo zestawów kołowych wymaga przeprowadzania systematycznych badań stanu technicznego zapewniających prawidłową eksploatację transportu szynowego. Przyczyniła się do tego m.in. katastrofa kolejowa w północnych Włoszech w miejscowości Viareggio w czerwcu 2009 r. Przyczyną katastrofy kolejowej było wykolejenia się pociągu wskutek pęknięcia i w następstwie złamania osi zestawu kołowego. Katastrofa pociągnęła duże straty materialne [1] Po tragicznym wypadku Europejska Agencja Kolejowa, Europejskie Władze Bezpieczeństwa i przewoźnicy towarowi wprowadziły zharmonizowane kryteria czego efektem było stworzenie Europejskiego Katalogu Inspekcji Wizualnej (EVIC). Badania wizualne w kolejnictwie stanowią podstawowe badania nieniszczące stanowiące podstawę do przeprowadzania innych badań. Przykład interpretacji oceny wizualnej z katalogu EVIC przedstawiono na rysunku 1.

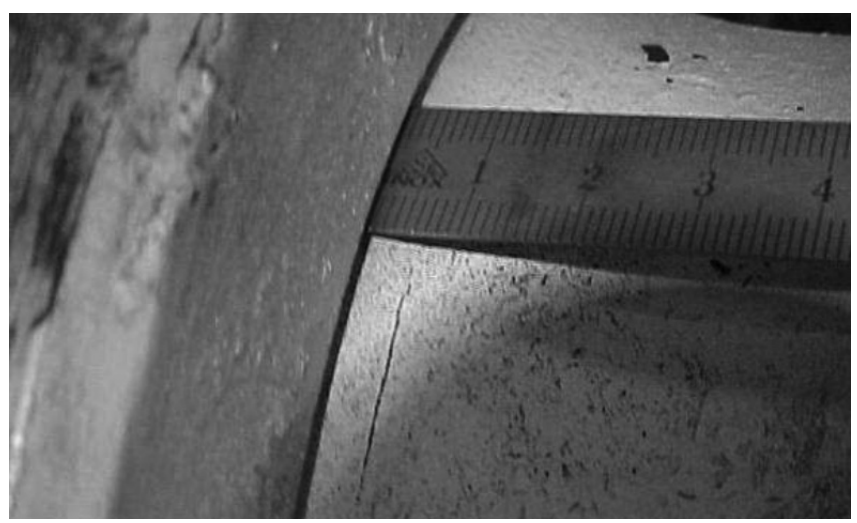

Rys. 1. Przykład ilustracji graficznej z katalogu EVIC oceny wizualnej pęknięcia w kategorii uszkodzeń mechanicznych na osiach niemalowanych [3]

Fig. 1. An example of graphic illustration of visual evaluation of a crack in the category of mechanical damage on unpainted axles from the European Visual Inspection Catalogue (EVIC) [3]

Dr hab. inż. Jacek Słania, prof. IS - Instytut Spawalnictwa, dr hab. inż. Andrzej Szymański - Politechnika Śląska, Instytut Spawalnictwa, mgr inż. tukasz Rawicki - Instytut Spawalnictwa. 
W sektorze kolejowym przeprowadza się również badania penetracyjne które mogą być wykonywane m.in. przy badaniu płytek manganowych wykorzystywanych przy regeneracji powierzchni maźnic. Badania prądami wirowymi służące do badania wieńców i wykorzystywane przy badaniach zautomatyzowanych, oraz badania radiograficzne wykorzystywane przy produkcji metra, tramwajów przy elementach o nieznacznej grubości. Spośród metod badań nieniszczących wykonywanych podczas produkcji i utrzymania pojazdów szynowych największe zastosowanie znalazły jednak badania magnetyczno-proszkowe MT i ultradźwiękowe UT. Doskonalenie metod badań defektoskopowych prowadzi do konieczności ciągłego szkolenia i kwalifikowania personelu wykonującego badania oraz certyfikacji według określonych w normach zasad. Wykonywanie badań magnetyczno-proszkowych i ultradźwiękowych powinno być wykonywane przez odpowiedni personel badań nieniszczących według uzgodnionej metody badawczej i przy pomocy dopuszczonej aparatury badawczej [1].

\section{Przebieg badań}

Celem przeprowadzanych badań jest wykrycie nieciągłości materiałowych powstałych zarówno podczas produkcji osi nowych jak i uszkodzeń osi powstałych przy eksploatacji zestawów kołowych. Do elementów pojazdów szynowych poddawanych badaniom nieniszczącym należą m.in. osie zestawów kołowych, koła, zestawy kołowe w eksploatacji, elementy łożysk tocznych, ostoje wagonów i lokomotyw, zbiorniki oraz ramy wózków. [2]
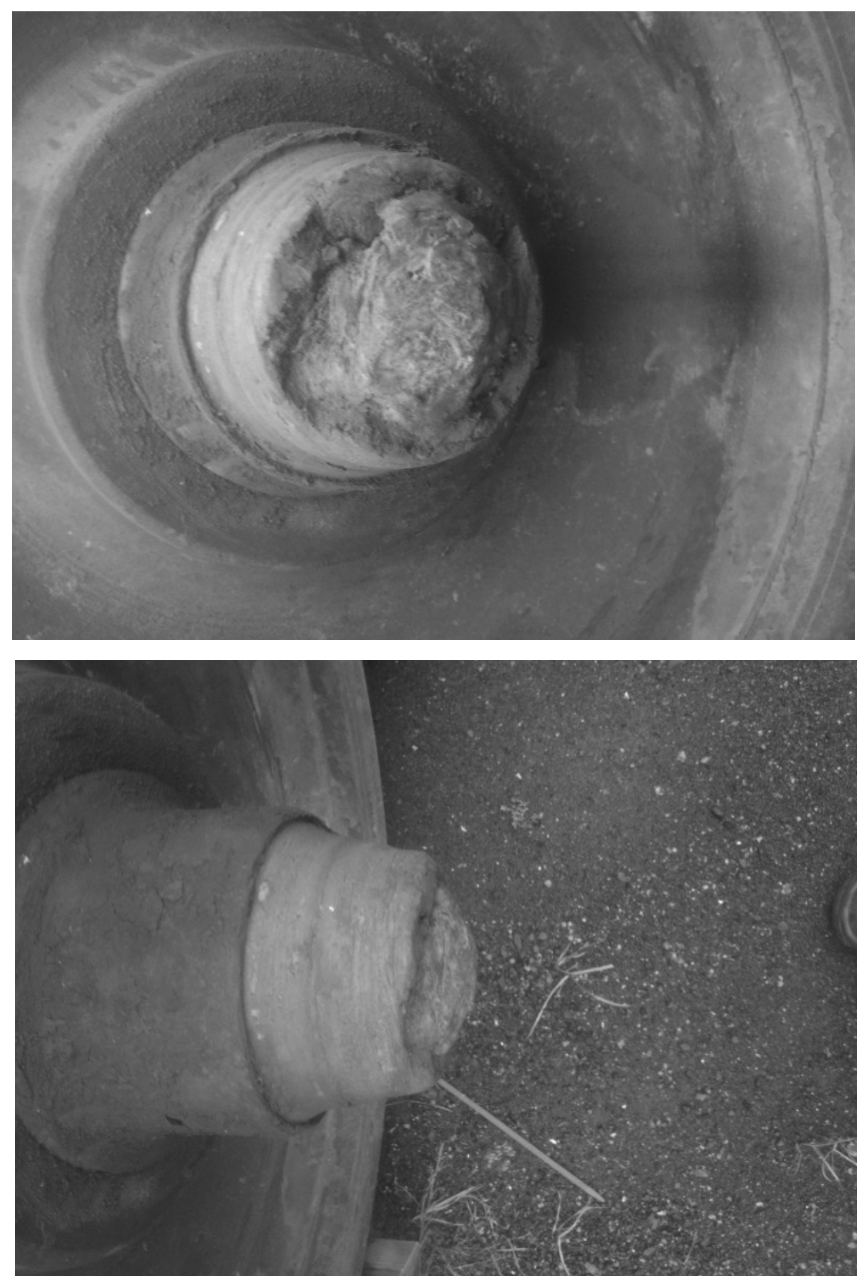

Rys. 2. Ukręcenie czopa osi kolejowej wskutek zatarcia łożyska Fig. 2. Twisting of a railway axle journal due to seizing of the bearing
Systematycznych badań wymagają zwłaszcza zestawy kołowe a badania ultradźwiękowe powinny zapewnić wykrycie poprzecznych pęknięć zmęczeniowych. Następstwem czego mogą być złamania osi co może doprowadzić do wykolejenia się pojazdu.

Zanieczyszczenie łożyska może doprowadzić do zakleszczenia a w konsekwencji do ukręcenia czopa osi co pokazano na rysunku 2 [1].

Zestawy kołowe spełniają szereg zadań m.in. umożliwiają ruch pojazdu, przenoszą ciężar pojazdu razem z ładunkiem, przenoszą obciążenia dynamiczne powodowane nierównością toru na elementy resorujące.

Przed przystąpieniem do badań ultradźwiękowych aparaturę badawczą należy podać kalibracji przy wykorzystaniu dopuszczonej osi wzorcowej danego typu i określenia odpowiedniej lokalizacji reflektorów odniesienia.

Szczególnie narażonymi na pęknięcia są obszary czopa osi oraz tarczy kola. Badania ultradźwiękowe w trakcie eksploatacji powinny być wykonywane po wybudowaniu i demontażu.[2]

Badania przeprowadzane są z cylindrycznych powierzchni bocznych przy wykorzystaniu głowic skośnych o kącie wprowadzania fal 37,45 i $54^{\circ}$, których celem jest wykrycie wad poprzecznych na całej długości.[1].

Usytuowanie osi kolejowej nieuzbrojonej do przeprowadzania badań ultradźwiękowych wraz z przykładami głowic pokazano na poniższych rysunkach 3 i 4.

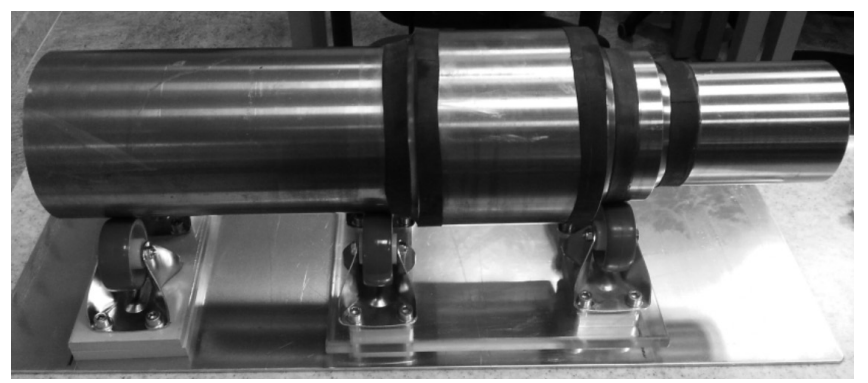

Rys. 3. Usytuowanie osi kolejowej nieuzbrojonej do przeprowadzania badań z powierzchni bocznej głowicami kątowymi

Fig. 3. Location of a railway axle for carrying out the tests from lateral surface with angle machining heads

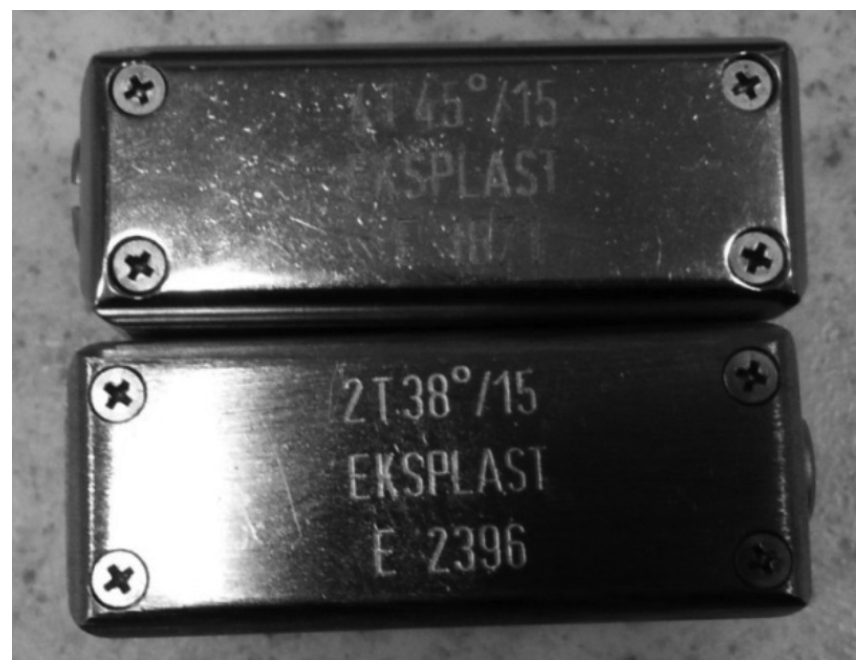

Rys. 4. Przykłady głowic wykorzystywanych do badania osi kolejowych z cylindrycznych powierzchni bocznych

Fig. 4. Examples of heads used for testing of railway axles from cylindrical lateral surfaces 
Badania przeprowadza się również z powierzchni czołowych osi głowicami normalnymi co pokazano na rysunku 5 oraz z nakładkami wykonanymi z pleksi o kątach dobranych do danego typu osi lub głowicami o dedykowanych kątach np. $23,26^{\circ}$ fali podłużnej.
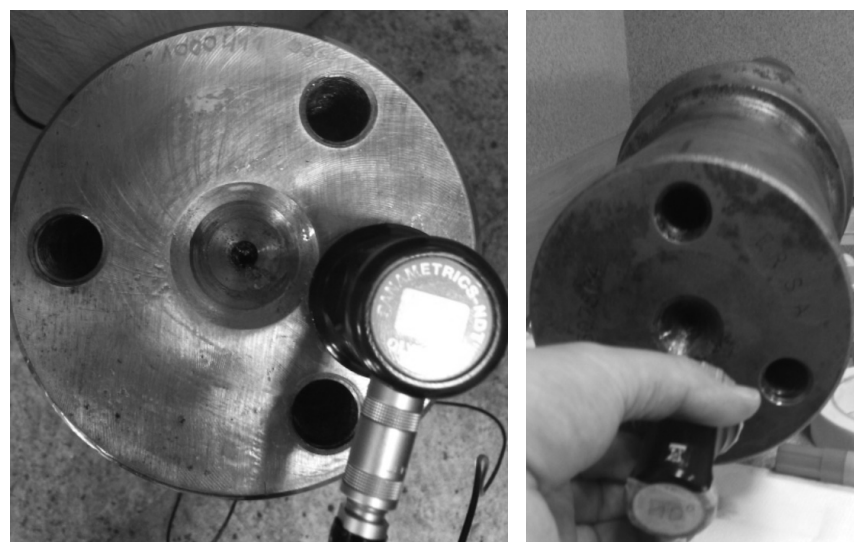

Rys. 5. Badanie osi z powierzchni czołowej głowicami normalnymi Fig. 5. Axle testing from face surface with normal heads

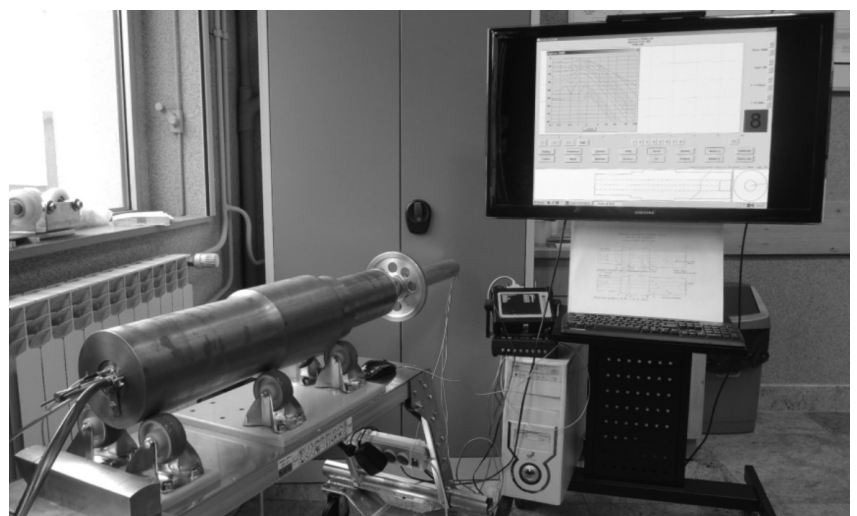

Rys. 6. Aparatura do badania osi drążonych z cylindrycznej powierzchni otworu osiowego

Fig. 6. The equipment for testing of hollow axles from cylindrical surface of axial opening
Badania wykonywane z powierzchni nakiełków za pomocą głowic skośnych ze stożkowymi specjalnymi powierzchniami dopasowanymi swym kształtem do nakiełków.

Ultradźwiękowe badania wykonywane są również na osiach drążonych z cylindrycznej powierzchni otworu osiowego specjalnymi głowicami skośnymi o kątach wprowadzenia fali 45 i $70^{\circ}$ badając całą powierzchnię osi. [1] Sposób przeprowadzania badania osi drążonej pokazano na rysunku 6.

Przed wykonaniem badań objętościowych jakimi są badania ultradźwiękowe przeprowadza się często badania powierzchniowe magnetyczno-proszkowe MT. Obszarem badań objęta jest cała objętość osi łącznie ze wszystkimi przejściami przekrojów. Badanie przeprowadzane jest zgodnie z wytycznymi odpowiednich norm. Prawidłowe badanie wymaga ustalenia prawidłowej wartości promieniowania ultrafioletowego oraz indukcji magnetycznej. Wady poprzeczne dla osi nowych są niedopuszczalne.[2]

Badania magnetyczno-proszkowe wykonuje się również na tarczach kół przy wykorzystaniu cewki MINDEN co pokazano na rysunku 7 .

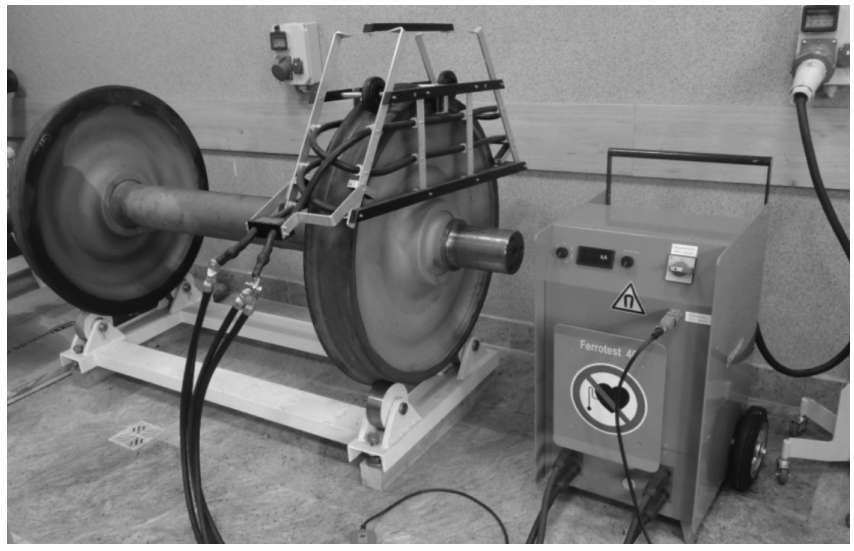

Rys. 7. Defektoskopia magnetyczno-proszkowa tarcz kół przy wykorzystaniu cewki MINDEN

Fig. 7. Magnetic particle inspection of wheel discs using MINDEN coil

\section{Podsumowanie}

Badania podzespołów pojazdów szynowych wprowadzają konieczność systematycznej kontroli osi zestawów kołowych co stanowi o bezpieczeństwie transportu szynowego. Osie kolejowe są obiektami trudnymi do badania jeżeli rozpatrywana jest jako element wchodzący w skład zestawu kołowego i elementy osadzone na osi generują dodatkowe echa podczas badań ultradźwiękowych. Ważnym ogniwem badan zestawów kołowych jest odpowiedni personel badawczy podany szkoleniom i procesowi certyfikacji poświadczający nabycie odpowiednich umiejętności do wykonywania badań. Przebycie odpowiedniego szkolenia i kwalifikacje na odpowiednim poziomie i stopniu kwalifikacji potwierdzone świadectwem certyfikującym zgodnie z PN-EN ISO 9712 stanowią konieczność przeprowadzania szkoleń w Sektorze Utrzymania Ruchu Kolei, na które powołuje się również norma UIC 960 dotycząca „Kwalifikacji i certyfikacji personelu dla badań nieniszczących części pojazdów i zespołów przy ich utrzymaniu".

Instytut Spawalnictwa w Gliwicach wybudował nowoczesne laboratorium do przeprowadzania szkoleń w sektorze Utrzymania Ruchu Kolei i wychodzi naprzeciw potrzebom i oczekiwaniom rynku kolejowego.

\section{Literatura}

[1] Grzegorz Hottowy - Wykrywanie pęknięć zmęczeniowych metodą ultradźwiękową w osiach pojazdów szynowych- - Przedsiębiorstwo EKSPLAST Sp.z o.o, Gliwice.2014r.

[2] Materiały szkoleniowe w badaniach UT sektor kolejowy- Henryk Nikraszewicz- Wagon Service Ostróda.
[3] Europejski Katalog Inspekcji Wizualnej (EVIC) dla osi wagonów towarowych.

[4] Wytyczne TDT i IS dotyczące szkolenia personelu badań nieniszczących w sektorze utrzymania ruchu kolei. 